\title{
Health-related quality of life in outpatients with primary central nervous system lymphoma after radiotherapy and high-dose methotrexate chemotherapy
}

\author{
YOSHIKO OKITA $^{1}$, YOSHITAKA NARITA ${ }^{2}$, YASUJI MIYAKITA ${ }^{2}$, \\ RURIKO MIYAHARA $^{2}$, MAKOTO OHNO ${ }^{2}$, MASAMICHI TAKAHASHI ${ }^{2}$, MASAHIRO NONAKA ${ }^{1,3}$, \\ YONEHIRO KANEMURA $^{1,4}$, SHIN NAKAJIMA ${ }^{1}$ and TOSHIYUKI FUJINAKA ${ }^{1}$ \\ ${ }^{1}$ Department of Neurosurgery, Osaka National Hospital, National Hospital Organization, Osaka 540-0006; \\ ${ }^{2}$ Department of Neurosurgery and Neuro-Oncology, National Cancer Center Hospital, Tokyo 104-0045; \\ ${ }^{3}$ Department of Neurosurgery, Kansai Medical University, Osaka 573-1191; ${ }^{4}$ Division of Regenerative Medicine, \\ Institute for Clinical Research, Osaka National Hospital, National Hospital Organization, Osaka 540-0006, Japan
}

Received February 10, 2016; Accepted April 20, 2016

DOI: $10.3892 / \mathrm{mco} .2016 .962$

\begin{abstract}
Chemoradiotherapy for primary central nervous system lymphoma (PCNSL) is associated with a considerable risk of long-term neurotoxicity. The present study aimed to assess the health-related quality of life (HRQOL) of outpatients with PCNSL who have received radiotherapy and high-dose methotrexate (HDMTX) chemotherapy, and to determine the factors that cause a decline in HRQOL and interfere with home living. A total of 37 patients were surveyed 0.9-14.2 years after their initial diagnosis and treatment. Each patient completed a multi-part HRQOL questionnaire that was used to examine the associations of HRQOL scores with leukoencephalopathy, Karnofsky performance status (KPS) scores, age, history of recurrence and HDMTX-based chemoradiotherapy. The results demonstrated that the history of recurrence, number of cycles of MTX chemotherapy and age affected the development of leukoencephalopathy. Reductions in KPS score were associated with a history of recurrence $(\mathrm{P}=0.03)$, but not with leukoencephalopathy $(\mathrm{P}=0.8)$. KPS score, leukoencephalopathy and age were significantly associated with a decline in HRQOL score. A decline in the HRQOL associated with a reduction in KPS score was also observed by multivariate analyses. Deterioration of the HRQOL among outpatients with PCNSL post-chemoradiotherapy was significantly associated with older age $(\geq 66$ years) and decreased KPS score. Older patients with a history of recurrence had a higher risk for deteriorated QOL
\end{abstract}

Correspondence to: Dr Yoshitaka Narita, Department of Neurosurgery and Neuro-Oncology, National Cancer Center Hospital, 5-1-1 Tsukiji, Chuo-ku, Tokyo 104-0045, Japan E-mail: yonarita@ncc.go.jp

Key words: health-related quality of life, outpatients, primary central nervous system lymphoma, Karnofsky performance status score, leukoencephalopathy due to development of leukoencephalopathy. Therefore, it is recommended that clinicians monitor the KPS score among outpatients with PCNSL. QOL examination for older patients with a lower KPS score was found to be particularly important for identifying any obstacles for home living.

\section{Introduction}

Whole-brain radiotherapy in combination with high-dose methotrexate (HDMTX)-based chemotherapy has resulted in long-term remissions and improved survival rates in patients with primary central nervous system lymphoma (PCNSL) (1). However, leukoencephalopathy is associated with a risk of neurotoxicity and may severely interfere with cognitive function $(2,3)$. Progressive leukoencephalopathy with cognitive deterioration is associated with a significant decrease in the quality of life (QOL) (4).

Health-related quality of life (HRQOL) has been recognized as an important measure in patients with primary brain tumors (5). Beyond the goal of prolonging survival, the treatment of patients with PCNSL aims to maintain or improve their well-being and HRQOL. HRQOL surveys have the potential to become a relevant method for evaluating the functional impairments resulting from the tumor as well as its treatment, as well as for obtaining information regarding the social and medical requirements of PCNSL patients. Previous studies demonstrated that lifestyle interventions have improved the HRQOL in cancer survivors $(6,7)$. While this type of assessment may be helpful to hospitalized patients, HRQOL surveys may be more important for improving the QOL of outpatients with PCNSL living at home.

The present study focused on determining the factors that contribute to a decline in QOL for outpatients with PCNSL, and elucidated the association of the Karnofsky performance status (KPS) score, leukoencephalopathy, disease recurrence, age and treatment with HRQOL.

This retrospective study was approved by the Institutional Review Board of the National Cancer Center and the Osaka 
National Hospital, National Hospital Organization. QOL evaluation was performed using medical interview sheets during routine care at our hospitals. All the patients whose QOL data were included in the study provided prior inclusive informed consent regarding medical research.

\section{Materials and methods}

Patients. Between April 2011 and April 2015, 37 patients with a history of PCNSL visited the visited the outpatient clinics of the National Cancer Center Hospital and the Osaka or Tokyo National Hospital, National Hospital Organization. Each patient completed the European Organization for Research and Treatment of Cancer (EORTC) Core 30 Questionnaire (QLQ-C30) and Brain Neoplasm Questionnaire (BN20). These patients were first diagnosed with PCNSL in Japan between December 2000 and November 2013 at the National Cancer Center Hospital (Tokyo, Japan) or at the Osaka National Hospital, National Hospital Organization (Osaka, Japan). The patients received high-dose methotrexate (HDMTX) chemotherapy $\left(3-5 \mathrm{~g} / \mathrm{m}^{2}\right)$, which was repeated every 2 weeks for a maximum of 5 cycles. After chemotherapy, patients received whole-brain radiotherapy. In case of relapse, the patients received 3-5 cycles of rituximab and HDMTX chemotherapy. Detailed information on all the patients is listed in Table I.

Questionnaires and data collection. Prior to data collection, the Institutional Review Board of each participating center approved the study protocol. The EORTC QLQ-C30 is an internationally validated instrument commonly used to assess the QOL in patients with cancer (8), whereas the EORTC QLQ-BN20 is a validated questionnaire for patients with primary brain tumors (9). HRQOL was assessed using the Japanese version of QLQ-C30 (version 3.0) (8) and QLQ-BN20 (9). These questionnaires were previously described by our group (10). We also evaluated KPS. KPS is a clinical score obtained from a numerical scale from 0 to 100 representing a patient's ability to perform daily and working activities, self-care, and the need for assistance (11).

Magnetic resonance imaging (MRI). Each patient underwent MRI every 2-3 months for the first 5 years from the timepoint of the patient's initial treatment, and every 6 months thereafter. The scale reported by Monaco et al (12) was used to evaluate white matter changes on MRI at the QOL survey. A grading scale was devised to assess imaging changes using T2 or fluid-attenuated image recovery sequences as follows: Grade 1, little or no white matter hyperintensity; grade 2, limited periventricular hyperintensity; and grade 3, diffuse white matter hyperintensity. Local white matter changes from specific tumors were not included (12).

Statistical analysis. A cross-sectional design was applied and the results were analyzed using JMP software, version 8 (SAS Institute Inc., Cary, NC, USA). The analysis was performed on all 37 cases. $\mathrm{P}<0.05$ was considered to indicate statistically significant differences. Multiple regression analysis was performed to evaluate the extent to which age, KPS, leukoencephalopathy and history of recurrence were independent risk factors for HRQOL.

\section{Results}

Patient characteristics. A total of 37 outpatients completed the questionnaires. The median age at the time of initial treatment was 63.0 years and the median age at the time of the QOL survey was 65.0 years (Table I). The median interval between initial diagnosis and QOL evaluation was 3.3 years (range, $0.9-14.2$ years). Of all the patients, $59.4 \%$ had a KPS score of $\geq 80$ at the time of diagnosis and $56.8 \%$ had a KPS score of $\geq 80$ at the time of the QOL evaluation. A total of 17 patients (46\%) had a higher KPS score at the time of the QOL evaluation compared with that at the time of initial diagnosis. Of the patients with improved KPS scores, 14 (82\%) had a KPS score of $\geq 80$ at the time of the QOL survey. Of the patients with improved KPS scores, 5 had a KPS $<80$ at initial diagnosis and their KPS score improved to $\geq 80$ during the subsequent QOL evaluation. In 13 patients (35\%), the KPS scores remained unchanged between the timepoint of diagnosis and their QOL evaluation, whereas 7 patients (19\%) exhibited a decline in their KPS score at the timepoint of QOL evaluation compared with that at diagnosis, and all these patients had a KPS score $<80$ at the time of the QOL survey. A total of 6 patients had a KPS score $<80$ at the time of the QOL evaluation, while having had a KPS score $\geq 80$ at initial diagnosis. A change in KPS score from diagnosis to QOL survey was associated with a history of recurrence $(\mathrm{P}=0.03)$ (Table II). The KPS at the time of the QOL survey was associated with the KPS at diagnosis $(\mathrm{P}=0.02)$ and with age at the time of the QOL survey $(\mathrm{P}=0.007)$ (Table II). A change in KPS score from diagnosis to the timepoint of the QOL survey was not correlated with leukoencephalopathy. Similarly, KPS at QOL was not correlated with leukoencephalopathy. With regard to leukoencephalopathy, 7 patients had grade 1, 21 had grade 2 and 9 had grade 3 disease at the time of the QOL survey. According to the univariate analysis, patients aged $\geq 65$ years developed significantly more severe white matter changes compared with those aged $<65$ years $(\mathrm{P}=0.03)$ (Table III). Furthermore, patients with a history of recurrence developed more white matter changes compared with those without recurrence $(\mathrm{P}=0.003)$ (Table III). Patients treated with $\geq 8$ cycles of MTX chemotherapy developed more white matter changes compared with those treated with $<8$ cycles $(\mathrm{P}=0.02)$ (Table III). However, according to the multivariate analysis, age, history of recurrence and the number of chemotherapy cycles did not affect the white matter changes.

QLQ-C30 and QLQ-BN20 scores compared with KPS scores, leukoencephalopathy and age at the time of QOL survey. As shown in Table IV, various QLQ-C30 functional status scores and symptom scores were significantly associated with the KPS scores at the time of the QOL survey, namely physical functioning $(\mathrm{P}<0.0001)$, role functioning $(\mathrm{P}<0.0001)$, cognitive functioning $(\mathrm{P}=0.01)$, social functioning $(\mathrm{P}=0.0005)$ and fatigue $(\mathrm{P}=0.003)$. In addition, the following key QLQ-BN20 symptoms were also associated with the KPS score: Visual disorder $(\mathrm{P}=0.04)$, motor dysfunction $(\mathrm{P}=0.03)$, communication deficit $(\mathrm{P}=0.0002)$, drowsiness $(\mathrm{P}=0.0001)$, leg weakness $(\mathrm{P}=0.004)$ and bladder control $(\mathrm{P}=0.005)$.

Various QLQ-C30 functional status scores were significantly associated with leukoencephalopathy (grade 1 vs. grade 2-3), namely physical functioning $(\mathrm{P}=0.009)$, role functioning $(\mathrm{P}=0.03)$, emotional functioning $(\mathrm{P}=0.01)$ 
Table I. Characteristics of patients with primary central nervous lymphoma.

\begin{tabular}{|c|c|c|c|}
\hline Characteristics & Number of patients & Years & Percentage \\
\hline \multicolumn{4}{|l|}{ Gender } \\
\hline Male & 25 & & 67.6 \\
\hline Female & 12 & & 32.4 \\
\hline \multicolumn{4}{|c|}{ Age at diagnosis (years) } \\
\hline Median & & 63 & \\
\hline Range & & $33-77$ & \\
\hline$\geq 60$ & 21 & & 56.8 \\
\hline \multicolumn{4}{|c|}{ Age at timepoint of QOL survey (years) } \\
\hline Median & & 65 & \\
\hline Range & & $39-81$ & \\
\hline$\geq 60$ & 26 & & 70.3 \\
\hline \multicolumn{4}{|l|}{ KPS at diagnosis } \\
\hline$\geq 80$ & 22 & & 59.5 \\
\hline$<80$ & 15 & & 40.5 \\
\hline \multicolumn{4}{|c|}{ KPS at timepoint of QOL survey } \\
\hline$\geq 80$ & 21 & & 56.8 \\
\hline$<80$ & 16 & & 43.2 \\
\hline \multicolumn{4}{|c|}{ Leukoencephalopathy } \\
\hline Grade 1 & 7 & & 18.9 \\
\hline Grade 2 & 21 & & 56.8 \\
\hline Grade 3 & 9 & & 24.3 \\
\hline \multicolumn{4}{|c|}{ History of recurrence at timepoint of QOL survey } \\
\hline+ & 16 & & 43.2 \\
\hline- & 21 & & 56.8 \\
\hline \multicolumn{4}{|c|}{ Additional chemotherapy at recurrence prior to QOL survey } \\
\hline+ & 12 & & 75.0 \\
\hline- & 4 & & 25.0 \\
\hline \multicolumn{4}{|c|}{ Time since diagnosis at timepoint of QOL survey (months) } \\
\hline Median & & 39.3 & \\
\hline Range & & $11.3-170.0$ & \\
\hline$\geq 5$ years & 10 & & 27.0 \\
\hline
\end{tabular}

and cognitive functioning $(\mathrm{P}=0.004)$. Similarly, several symptom scores were associated with leukoencephalopathy (grade 1 vs. grade 2-3): Fatigue $(\mathrm{P}=0.002)$, constipation $(\mathrm{P}=0.03)$ and financial difficulties $(\mathrm{P}=0.04)$. In addition, several key QLQ-BN20 characteristics were also associated with leukoencephalopathy (grade 1 vs. grade 2-3), such as future uncertainty $(\mathrm{P}=0.04)$, visual disorder $(\mathrm{P}=0.04)$ and leg weakness $(\mathrm{P}=0.04)$.

Various QLQ-C30 functional status scores and symptom scores were significantly associated with age at QOL survey (Table IV): Physical functioning $(\mathrm{P}=0.002)$, role functioning ( $\mathrm{P}=0.006)$, cognitive functioning $(\mathrm{P}=0.002)$, social functioning $(\mathrm{P}=0.03)$ and fatigue $(\mathrm{P}=0.03)$. The following key $\mathrm{QLQ}-\mathrm{BN} 20$ symptoms were also associated with the age at the time of QOL survey: Visual disorder $(\mathrm{P}=0.02)$, drowsiness $(\mathrm{P}=0.001)$ and leg weakness $(\mathrm{P}=0.02)$.

The time from initial diagnosis did not affect the decline in QOL. History of recurrence $(\mathrm{P}=0.048)$ and chemotherapy
$(\mathrm{P}=0.049)$ were only associated with fatigue and no other correlations were observed (Table IV).

Multivariate analysis. The multivariate analysis indicated that KPS scores were predictive of the QOL in terms of physical functioning $(\mathrm{P}<0.0001)$, role functioning $(\mathrm{P}=0.006)$, social functioning $(\mathrm{P}=0.009)$, fatigue $(\mathrm{P}=0.02)$, drowsiness $(\mathrm{P}=0.02)$ and leg weakness $(\mathrm{P}=0.02)($ Table $\mathrm{V})$. The age at the time of the QOL survey was predictive of the QLQ-C30 symptom scores for drowsiness $(\mathrm{P}=0.04)$. Leukoencephalopathy was predictive of the QLQ-C30 symptom scores for fatigue $(\mathrm{P}=0.008)$. Unlike age, leukoencephalopathy, history of recurrence and KPS score at the time of the QOL survey were predictive of various QOL-associated EORTC QLQ-C30 and BN20 scores.

Leukoencephalopathy. The multivariate analysis demonstrated that leukoencephalopathy rather than chemotherapy $(\mathrm{P}=0.3)$ or KPS score $(\mathrm{P}=0.8)$ was correlated with age at the time of the 
Table II. Correlation between changes in KPS score, KPS at diagnosis, KPS at QOL survey, age, leukoencephalopathy, history of recurrence and time from the treatment in patient with primary central nervous system lymphoma.

\begin{tabular}{|c|c|c|c|c|c|c|c|}
\hline \multirow[b]{2}{*}{ Variables } & \multicolumn{4}{|c|}{$\begin{array}{l}\text { Change in KPS score from diagnosis } \\
\text { to timepoint of QOL survey }\end{array}$} & \multicolumn{3}{|c|}{$\begin{array}{l}\text { KPS at } \\
\text { timepoint of QOL survey }\end{array}$} \\
\hline & Improvement & No change & Decline & P-value & $<80$ & $\geq 80$ & P-value \\
\hline KPS at diagnosis & & & & 0.3 & & & 0.02 \\
\hline$<80$ & 8 & 6 & 1 & & 10 & 5 & \\
\hline$\geq 80$ & 9 & 7 & 6 & & 6 & 16 & \\
\hline Age at QOL survey (years) & & & & 0.3 & & & 0.007 \\
\hline$<65$ & 10 & 4 & 3 & & 3 & 14 & \\
\hline$\geq 65$ & 7 & 9 & 4 & & 13 & 7 & \\
\hline History of recurrence at QOL survey & & & & 0.03 & & & 0.05 \\
\hline+ & 6 & 4 & 6 & & 10 & 6 & \\
\hline- & 11 & 9 & 1 & & 6 & 15 & \\
\hline Leukoencephalopathy & & & & 0.8 & & & 0.1 \\
\hline Grade 1 & 4 & 2 & 1 & & 1 & 6 & \\
\hline Grade 2-3 & 13 & 11 & 6 & & 15 & 15 & \\
\hline Time since diagnosis at QOL survey (years) & & & & 0.9 & & & 0.7 \\
\hline$<5$ & 13 & 9 & 5 & & 11 & 16 & \\
\hline$\geq 5$ & 4 & 4 & 2 & & 5 & 5 & \\
\hline
\end{tabular}

Table III. Correlation between leukoencephalopathy and patient age, history of recurrence, chemotherapy and KPS in patients with primary central nervous system lymphoma.

\begin{tabular}{|c|c|c|c|c|c|}
\hline & \multicolumn{3}{|c|}{ Leukoencephalopathy } & \multirow{2}{*}{$\frac{\text { Univariate }}{\text { P-value }}$} & \multirow{2}{*}{$\frac{\text { Multivariate }}{\text { P-value }}$} \\
\hline & Grade 1 & Grade 2 & Grade 3 & & \\
\hline Age at QOL survey (years) & & & & 0.03 & 0.09 \\
\hline$<65$ & 6 & 9 & 2 & & \\
\hline$\geq 65$ & 1 & 12 & 7 & & \\
\hline History of recurrence at QOL survey & & & & 0.003 & 0.07 \\
\hline+ & 1 & 7 & 8 & & \\
\hline- & 6 & 14 & 1 & & \\
\hline Chemotherapy prior to QOL survey & & & & 0.02 & 0.3 \\
\hline MTX $<8$ cycles & 7 & 16 & 4 & & \\
\hline MTX $\geq 8$ cycles & 0 & 5 & 5 & & \\
\hline KPS at QOL survey & & & & 0.09 & 0.8 \\
\hline$<80$ & 1 & 9 & 6 & & \\
\hline$\geq 80$ & 6 & 12 & 3 & & \\
\hline
\end{tabular}

QOL, quality of life; KPS, Karnofsky performance status; MTX, methotrexate.

QOL survey $(\mathrm{P}=0.09)$ and a history of recurrence $(\mathrm{P}=0.07)$, but the association was not significant (Table III).

\section{Discussion}

The present study suggested that a decline in HRQOL among outpatients with PCNSL is mainly associated with a decline in KPS score, leukoencephalopathy and older age ( $\geq 65$ years). Leukoencephalopathy was associated with recurrence, addi- tional chemotherapy and older age. A reduction in KPS scores was associated with recurrence in the outpatients.

In previous studies, KPS scores have been generally correlated with overall QOL in patients with brain tumors (11,13-15). KPS is an easy to assess and a reliable measure of functional status in cancer patients (16); however, it does not assess patients' difficulties with performing everyday activities when living at home. Furthermore, older patients tend to have lower KPS scores (14). In the present 


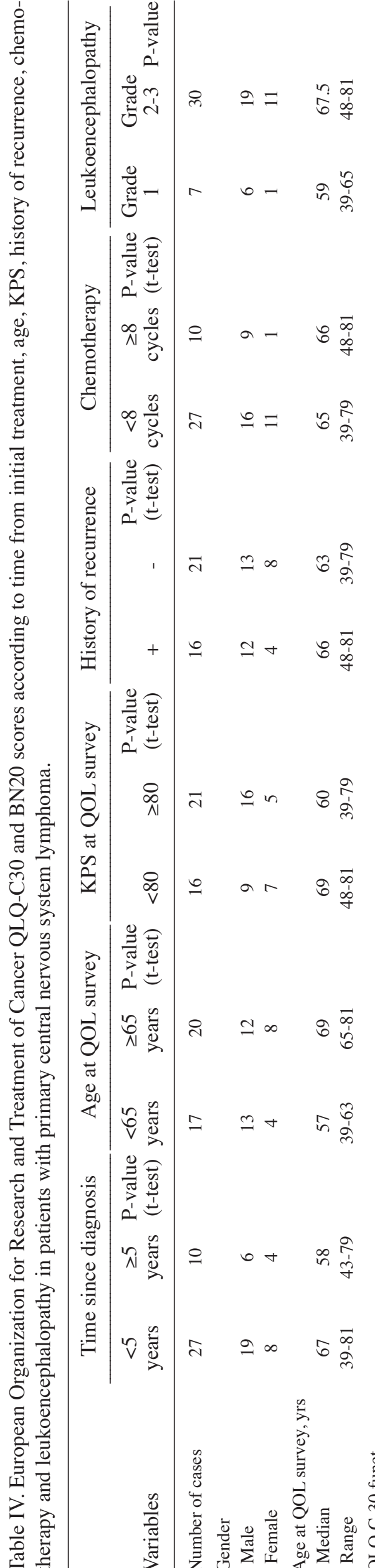

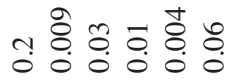

そे

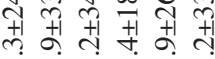
ठㅇ तु

ㄹ.

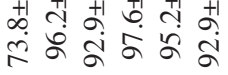
†ิ

$a, y+40$

กิ బิ

o. m 0 . m m

กิ ले

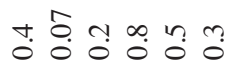

$\infty$ ก.

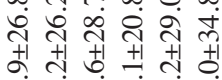

的过

n $0.0 .+\infty$

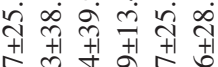

ठㅇ

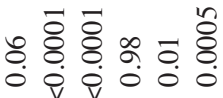

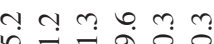

กิ

จें

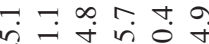

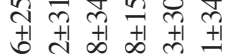

nं

ก

n 0 . $\infty$ a 0 in

సิ

in

ก. † $0 . \infty .0 .9$

กิ

$\infty \curvearrowleft \dot{\infty} \infty \dot{\infty}$

?

$\infty$ t. m $9 \infty$

กิ山े

ऊิํㅠ

$00 \div 0 \cdot 0$

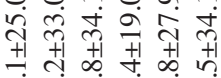
ఈ

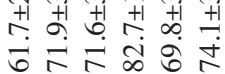

ஓै

r.

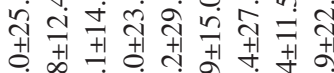

mे

†.

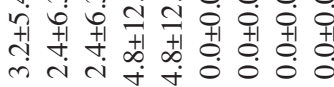

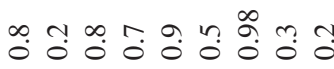

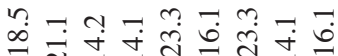

तु तं

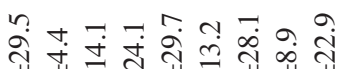

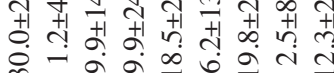

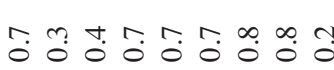

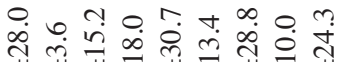

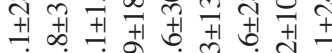

तें

战

H⿻

त่

§ैษ

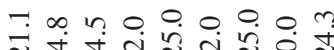

กํ.

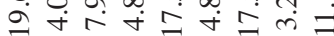

$\breve{\Delta}$ ำ

तิ $+\frac{7}{1}$ तो

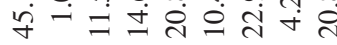

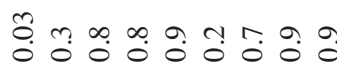

m 0 .

กิ

लें 0000

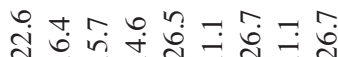

กิ

¿ें

ఈั

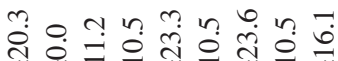

की

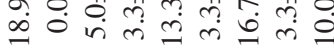

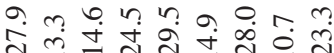

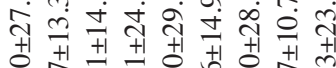

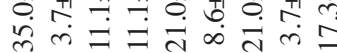

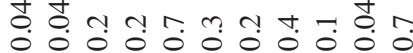
ᄀ ข

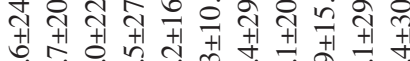
ฟ்

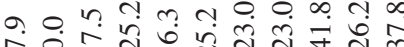
to $\begin{aligned} & 0 \\ & 0+1 \\ & 0\end{aligned}$ ○० ๙

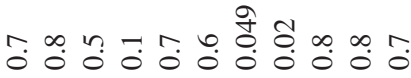

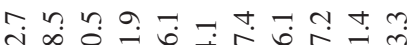

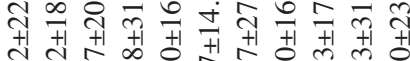
ป் ஸे

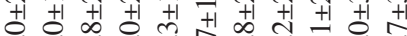

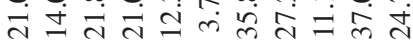

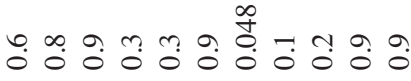
ம. तो ก ก ब -

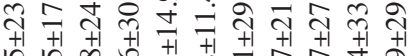
ปั

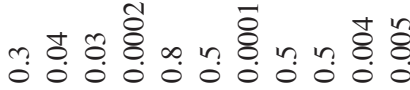

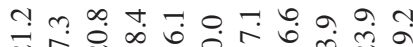
กิ

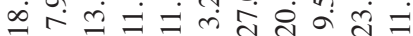
n $\infty . r-t \infty 0-\pi 0$ तิ

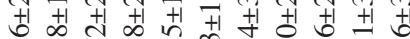

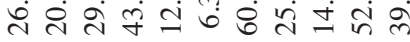

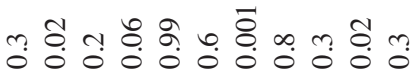
$0 \mathrm{~m} n \mathrm{n} m \mathrm{n}$ a m $\mathrm{n}$ a กิ ते

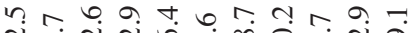
กิบ In "ᄑ గุ

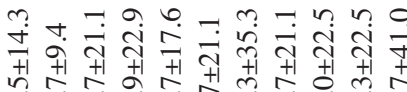
ป - +r m n กิบ ๗઼

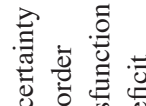

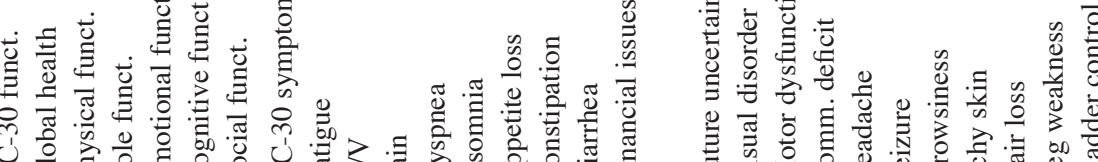

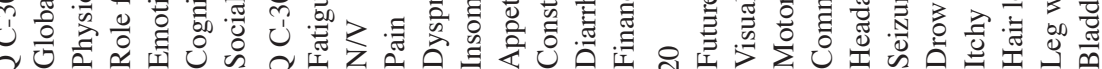

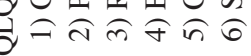


Table V. Multivariate and univariate analyses of European Organization for Research and Treatment of Cancer QLQ-C30 and BN20 score in patients with primary central nervous system lymphoma.

\begin{tabular}{|c|c|c|c|c|}
\hline \multirow[b]{2}{*}{ Variables } & \multirow[b]{2}{*}{ Associated factors } & \multirow{2}{*}{$\frac{\text { Univariate }}{\text { P-value (t-test) }}$} & \multicolumn{2}{|c|}{$\begin{array}{l}\text { Multivariate (multi } \\
\text { regression analysis) }\end{array}$} \\
\hline & & & $\mathrm{t}$ & P-value \\
\hline \multicolumn{5}{|l|}{ QLQ C-30 functioning } \\
\hline \multirow[t]{4}{*}{ 2) Physical functioning } & Age at QOL survey & 0.002 & -0.84 & 0.4 \\
\hline & KPS at QOL survey & $<0.0001$ & 5.00 & $<0.0001$ \\
\hline & Leukoencephalopathy & 0.009 & 1.61 & 0.1 \\
\hline & History of recurrence & 0.07 & -0.10 & 0.9 \\
\hline \multirow[t]{4}{*}{ 3) Role functioning } & Age at QOL survey & 0.006 & -0.94 & 0.4 \\
\hline & KPS at QOL survey & $<0.0001$ & 2.98 & 0.006 \\
\hline & Leukoencephalopathy & 0.03 & 1.07 & 0.3 \\
\hline & History of recurrence & 0.2 & 0.06 & 0.9 \\
\hline \multirow[t]{4}{*}{ 5) Cognitive functioning } & Age at QOL survey & 0.002 & -1.72 & 0.09 \\
\hline & KPS at QOL survey & 0.01 & 1.28 & 0.2 \\
\hline & Leukoencephalopathy & 0.004 & 1.99 & 0.05 \\
\hline & History of recurrence & 0.5 & 0.67 & 0.5 \\
\hline \multirow[t]{4}{*}{ 6) Social functioning } & Age at QOL survey & 0.03 & -0.38 & 0.7 \\
\hline & KPS at QOL survey & 0.0005 & 2.79 & 0.009 \\
\hline & Leukoencephalopathy & 0.06 & 1.02 & 0.3 \\
\hline & History of recurrence & 0.3 & 0.28 & 0.8 \\
\hline \multicolumn{5}{|l|}{ QLQ C-30 symptoms } \\
\hline \multirow[t]{4}{*}{ 7) Fatigue } & Age at QOL survey & 0.03 & 0.18 & 0.9 \\
\hline & KPS at QOL survey & 0.003 & -2.54 & 0.02 \\
\hline & Leukoencephalopathy & 0.002 & -2.84 & 0.008 \\
\hline & History of recurrence & 0.7 & -1.35 & 0.2 \\
\hline \multicolumn{5}{|l|}{ BN20 } \\
\hline \multirow[t]{4}{*}{ 2) Visual disorder } & Age at QOL survey & 0.02 & 0.99 & 0.3 \\
\hline & KPS at QOL survey & 0.04 & -1.39 & 0.2 \\
\hline & Leukoencephalopathy & 0.04 & -1.57 & 0.1 \\
\hline & History of recurrence & 0.8 & -1.41 & 0.2 \\
\hline \multirow[t]{4}{*}{ 7) Drowsiness } & Age at QOL survey & 0.001 & 2.12 & 0.04 \\
\hline & KPS at QOL survey & 0.0001 & -2.44 & 0.02 \\
\hline & Leukoencephalopathy & 0.2 & 0.44 & 0.7 \\
\hline & History of recurrence & 0.048 & 1.14 & 0.3 \\
\hline \multirow[t]{4}{*}{ 10) Leg weakness } & Age at QOL survey & 0.02 & 0.70 & 0.5 \\
\hline & KPS at QOL survey & 0.004 & -2.40 & 0.02 \\
\hline & Leukoencephalopathy & 0.04 & -1.55 & 0.1 \\
\hline & History of recurrence & 0.9 & -1.57 & 0.1 \\
\hline
\end{tabular}

QOL, quality of life; KPS, Karnofsky performance status.

study, the KPS scores of patients aged $<65$ years were significantly higher compared with those of patients aged $\geq 65$ at the time of the QOL survey. Low KPS score appear to indicative of a deterioration in the QOL of the outpatients with PCNSL. QOL assessment is therefore recommended for older patients with lower KPS scores, as it is crucial to identify any obstacles for home living.

Hoang-Xuan et al (17) assessed the efficacy and toxicity of chemotherapy alone in patients with PCNSL aged $>60$ years. Their aim was to avoid or at least delay radiotherapy. They reported that $12 \%$ of patients with PCNSL aged $>60$ years had decreased KPS scores, 52\% had stable scores and 36\% exhibited an increase in their score. Treatment-related cognitive decline occurred in $8 \%$ of patients and a performance status decline occurred in $12 \%$ of the patients; however, in the majority of the patients, cognitive function and performance status were maintained or improved until disease progression (17). In the present study, all the patients had received radiotherapy and HDMTX chemotherapy prior to the QOL survey. In the majority of the patients, the KPS score was maintained $(35 \%)$ or improved (46\%) between the time of diagnosis and QOL evaluation. Of the 21 patients who had no recurrence, 14 had a KPS score of $\geq 80$ at initial diagnosis, and only $1(7.1 \%)$ of the 14 patients exhibited a decrease in the KPS score. Of 16 patients who had recurrence, 8 had a KPS score $\geq 80$ at the time of initial diagnosis and relapsed prior to the QOL survey; 5 of them exhibited a decline in the KPS score. A reduction in KPS scores was correlated with a history of recurrence at the time of the QOL 
survey. According to the results of the present study, the QOL of outpatients with a stable KPS score appeared to deteriorate whenever a recurrence occurred. Furthermore, Abray et al (18) reported that patients aged $>60$ years who received radiotherapy were at a significantly higher risk of delayed neurotoxicity (83\%) and a reduction of the KPS score. In the present study, KPS scores were associated with age at the time of the QOL survey. KPS score at the time of the QOL survey declined in older patients who survived after chemoradiotherapy.

Omuro et al (4) reported that age $\geq 60$ years was a statistically significant risk factor for developing neurotoxicity. Kiewe et al (19) evaluated surviving patients without evidence of lymphoma or late neurotoxicity, and reported a positive correlation between radiological and clinical abnormalities. White matter abnormalities on MRI were associated with whole-brain radiotherapy and corresponded with poorer performance in attention/executive function, verbal memory, motor skills and poorer self-perceived QOL (20). By contrast, Fliessbach et al (21) reported that neurological symptoms were not associated with leukoencephalopathy. In the present study, leukoencephalopathy was not found to be significantly associated with a reduction in KPS scores, but was significantly asociated with various QLQ-C30 functional status scores. Furthermore, leukoencephalopathy was significantly correlated with older age, a history of recurrence and chemotherapy.

The limitations of the present study included a small sample size of outpatients with stable KPS scores. A decrease in the KPS score was a key indicator for the decline in QOL of the outpatients. QOL assessment in older patients with lower KPS score is crucial for identifying any obstacles for home living.

In conclusion, the present results suggest that a decline in the HRQOL among outpatients with PCNSL is mainly associated with a reduction in KPS scores as well as leukoenchephalopathy and older age ( $\geq 65$ years). A decline in KPS scores was associated with recurrence in the outpatients. Older patients with a history of recurrence are at the highest risk for a decline in QOL due to development of leukoencephalopathy.

\section{Acknowledgements}

The present study was supported by a Grant-in-Aid for Scientific Research from the Ministry of Education, Science and Culture of Japan (no. 15K10350 to Y.N.).

\section{References}

1. DeAngelis LM, Seiferheld W, Schold SC, Fisher B and Schultz CJ; Radiation Therapy Oncology Group Study 93-10: Combination chemotherapy and radiotherapy for primary central nervous system lymphoma: Radiation therapy oncology group study 93-10. J Clin Oncol 20: 4643-4648, 2002.

2. Angelov L, Doolittle ND, Kraemer DF, Siegal T, Barnett GH, Peereboom DM, Stevens G, McGregor J, Jahnke K, Lacy CA, et al: Blood-brain barrier disruption and intra-arterial methotrexate-based therapy for newly diagnosed primary CNS lymphoma: A multi-institutional experience. J Clin Oncol 27: 3503-3509, 2009.

3. Thiel E, Korfel A, Martus P, Kanz L, Griesinger F, Rauch M, Röth A, Hertenstein B, von Toll T, Hundsberger T, et al: High-dose methotrexate with or without whole brain radiotherapy for primary CNS lymphoma (G-PCNSL-SG-1): A phase 3, randomised, non-inferiority trial. Lancet Oncol 11: 1036-1047, 2010.
4. Omuro AM, Ben-Porat LS, Panageas KS, Kim AK, Correa DD, Yahalom J, Deangelis LM and Abrey LE: Delayed neurotoxicity in primary central nervous system lymphoma. Arch Neurol 62: 1595-1600, 2005

5. Taphoorn MJ, Stupp R, Coens C, Osoba D, Kortmann R, van den Bent MJ, Mason W, Mirimanoff RO, Baumert BG, Eisenhauer E, et al: Health-related quality of life in patients with glioblastoma: A randomised controlled trial. Lancet Oncol 6: 937-944, 2005.

6. Morey MC, Snyder DC, Sloane R, Cohen HJ, Peterson B, Hartman TJ, Miller P, Mitchell DC and Demark-Wahnefried W: Effects of home-based diet and exercise on functional outcomes among older, overweight long-term cancer survivors: RENEW: A randomized controlled trial. JAMA 301: 1883-1891, 2009.

7. Nock NL, Owusu C, Flocke S, Krejci SA, Kullman EL, Austin K, Bennett B, Cerne S, Harmon C, Moore H, et al: A Community-Based exercise and support group program improves quality of life in African-American breast cancer survivors: A quantitative and qualitative analysis. Int J Sports Exerc Med 1: pii; 020, 2015.

8. Aaronson NK, Ahmedzai S, Bergman B, Bullinger M, Cull A, Duez NJ, Filiberti A, Flechtner H, Fleishman SB, de Haes JC, et al: The European organization for research and treatment of cancer QLQ-C30: A quality-of-life instrument for use in international clinical trials in oncology. J Natl Cancer Inst 85: 365-376, 1993.

9. Taphoorn MJ, Claassens L, Aaronson NK, Coens C, Mauer M, Osoba D, Stupp R, Mirimanoff RO, van den Bent MJ and Bottomley A; EORTC Quality of Life Group, and Brain Cancer, NCIC and Radiotherapy Groups: An international validation study of the EORTC brain cancer module (EORTC QLQ-BN20) for assessing health-related quality of life and symptoms in brain cancer patients. Eur J Cancer 46: 1033-1040, 2010.

10. Okita Y, Narita Y, Miyahara R, Miyakita Y, Ohno M and Shibui S: Health-related quality of life in long-term survivors with Grade II gliomas: The contribution of disease recurrence and Karnofsky Performance Status. Jpn J Clin Oncol 45: 906-913, 2015.

11. Schiavolin S, Quintas R, Pagani M, Brock S, Acerbi F, Visintini S, Cusin A, Schiariti M, Broggi M, Ferroli P and Leonardi M: Quality of life, disability, well-being, and coping strategies in patients undergoing neurosurgical procedures: Preoperative results in an Italian sample. Sci World J 2014: 790387, 2014.

12. Monaco EA III, Faraji AH, Berkowitz O, Parry PV, Hadelsberg U, Kano H, Niranjan A, Kondziolka D and Lunsford LD: Leukoencephalopathy after whole-brain radiation therapy plus radiosurgery versus radiosurgery alone for metastatic lung cancer. Cancer 119: 226-232, 2013.

13. Cheng JX, Liu BL, Zhang X, Lin W, Zhang YQ, Liu WP, Zhang JN, Lin H, Wang R and Yin H: Health-related quality of life in glioma patients in China. BMC Cancer 10: 305, 2010.

14. Mackworth N, Fobair P and Prados MD: Quality of life self-reports from 200 brain tumor patients: Comparisons with Karnofsky performance scores. J Neurooncol 14: 243-253, 1992.

15. Recht L, Glantz M, Chamberlain M and Hsieh CC: Quantitative measurement of quality outcome in malignant glioma patients using an independent living score (ILS). Assessment of a retrospective cohort. J Neurooncol 61: 127-136, 2003.

16. Mor V, Laliberte L, Morris JN and Wiemann M: The karnofsky performance status scale. An examination of its reliability and validity in a research setting. Cancer 53: 2002-2007, 1984.

17. Hoang-Xuan K, Taillandier L, Chinot O, Soubeyran P, Bogdhan U, Hildebrand J, Frenay M, De Beule N, Delattre JY and Baron B; European Organization for Research and Treatment of Cancer Brain Tumor Group: Chemotherapy alone as initial treatment for primary CNS lymphoma in patients older than 60 years: A multicenter phase II study (26952) of the European organization for research and treatment of cancer brain tumor group. J Clin Oncol 21: 2726-2731, 2003.

18. Abrey LE, Yahalom J and DeAngelis LM: Treatment for primary CNS lymphoma: The next step. J Clin Oncol 18: 3144-3150, 2000.

19. Kiewe P, Fischer L, Martus P, Thiel E and Korfel A: Primary central nervous system lymphoma: Monocenter, long-term, intent-to-treat analysis. Cancer 112: 1812-1820, 2008.

20. Doolittle ND, Korfel A, Lubow MA, Schorb E, Schlegel U, Rogowski S, Fu R, Dósa E, Illerhaus G, Kraemer DF, et al: Long-term cognitive function, neuroimaging, and quality of life in primary CNS lymphoma. Neurology 81: 84-92, 2013.

21. Fliessbach K, Helmstaedter C,Urbach H, et al: Neuropsychological outcome after chemotherapy for primary CNS lymphoma: A prospective study. Neurology 64: 1184-1188, 2005. 